\title{
Spatial Distribution of Reniform Nematode in Cotton as Influenced by Soil Texture and Crop Rotations
}

\author{
Claudia M. Holguin, Patrick Gerard, John D. Mueller, Ahmad Khalilian, and Paula Agudelo
}

First and fifth authors: School of Agricultural, Forest, and Environmental Sciences, Clemson University, Clemson, SC 29634; second author: Department of Mathematical Sciences, Clemson University, Clemson, SC 29634; and third and fourth authors: Edisto Research and Education Center, Clemson University, Blackville, SC 29817.

Accepted for publication 12 November 2014.

\begin{abstract}
Holguin, C. M., Gerard, P., Mueller, J. D., Khalilian, A., and Agudelo, P. 2015. Spatial distribution of reniform nematode in cotton as influenced by soil texture and crop rotations. Phytopathology 105:674-683.

Reniform nematode (RN) is an important pest in cotton production. Knowledge of the distribution patterns of $\mathrm{RN}$ is essential for selecting sampling strategies and for site-specific management. A 3-year study was conducted in two fields in South Carolina with the purpose of characterizing the distribution of $\mathrm{RN}$ using a fine-scale sampling scheme in plots representing different soil textures (field 1), and using a largescale arbitrary sampling scheme (field 2). Horizontal distribution data showed an aggregated pattern of RN densities at planting and after

harvest in both fields each year, with patches ranging from 8 to $12 \mathrm{~m}$. However, a significant neighborhood structure was only detected when suitable hosts (cotton and soybean) were planted. Correlations between RN densities and percent sand and silt were detected, showing nematode densities peaked when sand content was around $60 \%$ and declined when sand content increased above 60 to $65 \%$. When fewer samples were taken in the field with more uniform sand content, percentage of sand was a less reliable predictor of RN densities. Vertical sampling showed the highest numbers of RN were found at 15 to $30 \mathrm{~cm}$ deep after cotton, but were deeper after a nonhost crop. Understanding distribution patterns of RN within a field may improve the effectiveness of management practices.
\end{abstract}

Rotylenchulus reniformis, reniform nematode (RN), is an important pest of upland cotton (Gossypium hirsutum) causing losses in both yield and quality $(4,13,20,45)$. In the United States, it is considered the primary nematode pest of upland cotton in several southeastern states $(10,13,16,23,37)$. In $2012, \mathrm{RN}$ caused estimated losses of 58,503 metric tons (268,698 bales) of U.S. production (5). Management of RN currently relies on crop rotation and chemical control (34). Commonly prescribed rotations for management of RN include resistant soybean (Glycine max), and nonhost crops such as peanut (Arachis hypogea), corn (Zea mays), and sorghum (Sorghum bicolor) $(9,11,39)$. Nematicides and crop rotation can decrease RN densities and limit losses during a given season, but sharp increases in RN numbers occur when cotton is returned as a host $(9,11,39)$, making it necessary to repeat treatments yearly (20).

Site-specific application of nematicides has been proposed as a strategy to manage RN more efficiently in cotton agroecosystems $(8,34)$. Limiting nematicide applications to target areas where the nematode is above threshold can reduce environmental contamination and decrease costs of production $(8,30,34)$. Site-specific nematode management involves defining management zones based on soil factors and assigning a risk level to each zone $(31,34)$. For example, a soil electrical conductivity $\left(\mathrm{EC}_{\mathrm{a}}\right)$ meter can be used to generate $\mathrm{EC}_{\mathrm{a}}$ geo-referenced maps that display zones in the field with similar soil textures $(19,34)$ and be used as the basis for management zone delineation. Soil $\mathrm{EC}_{\mathrm{a}}$ has been shown to successfully infer soil texture and nematode densities for a number of species $(2,19,34,36)$. Soil particle size (texture) and structure (arrangement of soil pores) are considered two of the main driving forces affecting the distribution of plant-parasitic nematodes in a field $(2,3,7,31,51)$. Population densities of Meloidogyne incognita, Hoplolaimus columbus, and Heterodera

Corresponding author: P. Agudelo; E-mail address: pagudel@clemson.edu glycines in field crops have been shown to be positively correlated to sand content in soils $(3,7,19,31,32,38)$. In contrast, RN population densities have been reported to be positively correlated to levels of silt or clay $(9,12,20,21,33,44)$, although discrepancies among reports are evident. Robinson et al. (44) conducted a survey in the Lower Rio Grande Valley and reported that RN was mainly present in clay silt and clay soils, and that the geographical distribution of $\mathrm{RN}$ was not driven by the presence of the host. Similarly, Moore and Lawrence (33) and Davis et al. (8) found higher RN reproduction in finer textured soils. However, another study by Koenning et al. (21) found that reproduction of RN was greater in loamy sand soils with intermediate percentages of clay and silt, and Herring et al. (14) also reported higher densities of $\mathrm{RN}$ associated with sandy loam soils.

Information published thus far on relationships between $\mathrm{RN}$ and soil texture has been mainly inferred from survey data, microplot studies, or greenhouse experiments, and there is insufficient information on distribution patterns of $\mathrm{RN}$ in fields. For successful use of site-specific nematode management tactics, it is essential to understand the spatial distribution patterns influencing the presence and abundance of the species of interest and the factors driving such distribution. Our objective was to study the spatial distribution of RN in the field, as influenced by crop, time of sampling, and soil texture. Specifically, we characterized (i) the spatial distribution of RN using a fine-scale sampling scheme in field plots representing different soil textures as inferred by $\mathrm{EC}_{\mathrm{a}}$ data (i.e., potential management zones), and (ii) the horizontal and vertical distribution of RN using a largescale arbitrary sampling scheme.

\section{MATERIALS AND METHODS}

The study was conducted from spring 2011 to winter 2013 in two commercial fields: field 1 (36.4 ha) located near Bishopville, South Carolina $\left(80.648^{\circ} \mathrm{W}, 33.736^{\circ} \mathrm{N}\right)$ and field $2(44.5 \mathrm{ha})$ located near Ft. Motte, South Carolina $\left(80.199^{\circ} \mathrm{W}, 34.142^{\circ} \mathrm{N}\right)$. Both fields used minimum tillage practices (strip-tilling). 
Field 1: Fine-scale sampling. Field 1 was irrigated and planted with cotton 'Deltapine 1050' in 2011, followed by corn 'Pioneer 1690' in 2012 and soybean 'Asgrow 7231' in 2013. Prior to planting (April 2011), soil $\mathrm{EC}_{\mathrm{a}}$ readings were taken with a sensor cart (Veris 3100 from Veris Technologies, Salina, KS). Three pairs of coulter electrodes produced an electrical current when making contact with the soil. One pair of coulters introduced a current at a set voltage into the soil while the other two measured the drop of voltage, producing $\mathrm{EC}_{\mathrm{a}}$ readings at two soil depths simultaneously: 0 to $30 \mathrm{~cm}$ (shallow) and 0 to $90 \mathrm{~cm}$ (deep). Using global positioning system (GPS) technology and mapping sensors, each point in the field where the $\mathrm{EC}_{\mathrm{a}}$ value was taken was geo-referenced to create a map. The sensor cart was passed every $18 \mathrm{~m}$ for an average of $4,550 \mathrm{EC}_{\mathrm{a}}$ data points. The generated map was divided into seven sections according to shallow $\mathrm{EC}_{\mathrm{a}}$ value ranges (Fig. 1A). The minimum shallow $\mathrm{EC}_{\mathrm{a}}$ value was $1.5 \mathrm{mS} / \mathrm{m}$ and the maximum 31.4 $\mathrm{mS} / \mathrm{m}$ (Table 1). For nematode sampling, four zones of the field were selected to represent different $\mathrm{EC}_{\mathrm{a}}$ readings and corresponding inferred textures. In each zone, plots of $40 \times 16 \mathrm{~m}$ were divided into 40 subplots of $4 \times 4 \mathrm{~m}$. Soil samples were collected from 20 subplots in each plot (Fig. 1B) at planting (May 2011 and August 2013) and after harvest (December 2011 and December 2013). In 2012 (corn), only after harvest samples were collected in September 2012. Each soil sample consisted of four subsamples taken from within a onesquare-meter area at $15 \mathrm{~cm}$ deep and composited into a single sample, for a total of 80 samples per date.

Field 2: Large-scale sampling. Field 2 was not irrigated and was planted with cotton 'Deltapine 1050' in 2012 followed by peanut 'NC-v11' in 2013. For this field, sampling was conducted at arbitrary locations evenly distributed across the field without a previous $\mathrm{EC}_{\mathrm{a}}$ map. Coordinates of the sampling locations were noted and used for subsequent sampling. The $\mathrm{EC}_{\mathrm{a}}$ values were taken at each sampling point after harvest (November 2013) the last year of the experiment (Table 1). Soil samples were collected at planting
(May 2012 and May 2013) and after harvest (December 2012 and December 2013). Each soil sample consisted of four subsamples taken from within a one-square-meter area at $15 \mathrm{~cm}$ deep and composited into a single sample, for a total of 40 samples per date. Additionally, vertical core samples $(1 \mathrm{~m}$ deep and $\times 4.3 \mathrm{~cm}$ in diameter) were collected each year after harvest in 21 points of the field. Vertical core samples were taken with a hydraulic soil sampler (GSTS, Giddings Machine Company, Fort Collins, CO) mounted on a tractor. Each core was divided into four sections that were processed separately: 0 to $15 \mathrm{~cm}, 15$ to $30 \mathrm{~cm}, 30$ to $60 \mathrm{~cm}$, and below $60 \mathrm{~cm}$.

For both fields, nematodes were extracted from all soil samples by sugar centrifugal flotation (15) and soil particle distribution (percentage of sand, silt, and clay content) was determined using the Bouyoucos method (6). The soil texture determined in the first at plant sampling was used to decide the location of the 21 vertical sampling sites in field 2. Seven cores were taken from locations representing each of the three soil types found in the field: sandy loam, sandy clay loam, and loamy sand.

Statistical analysis. Descriptive data analysis of shallow $\mathrm{EC}_{\mathrm{a}}$ readings and soil particle size distribution was performed for soil characterization in each plot in field 1 and all soil samples in field 2 . To analyze RN densities across sampling dates, densities were transformed with $\log _{10}(x+1)$ to standardize the variance prior to analysis of variance (ANOVA). A two-way ANOVA was performed with plot and sampling dates as factors for field 1, and a one-way ANOVA was used with sampling date as a fixed effect for field 2. For both fields, date was included as a repeated measures statement with a first-order autoregressive covariance structure (PROC MIXED) (SAS Institute, Cary, NC). For means separation, the Tukey's honest significant difference test was used with 0.05 level of significance.

To determine the distribution of $\mathrm{RN}$ in each field, the variance-tomean ratio (VMR) was used as a dispersal index (DI) $(48,49)$. This index takes into account the nematode counts per sample unit and
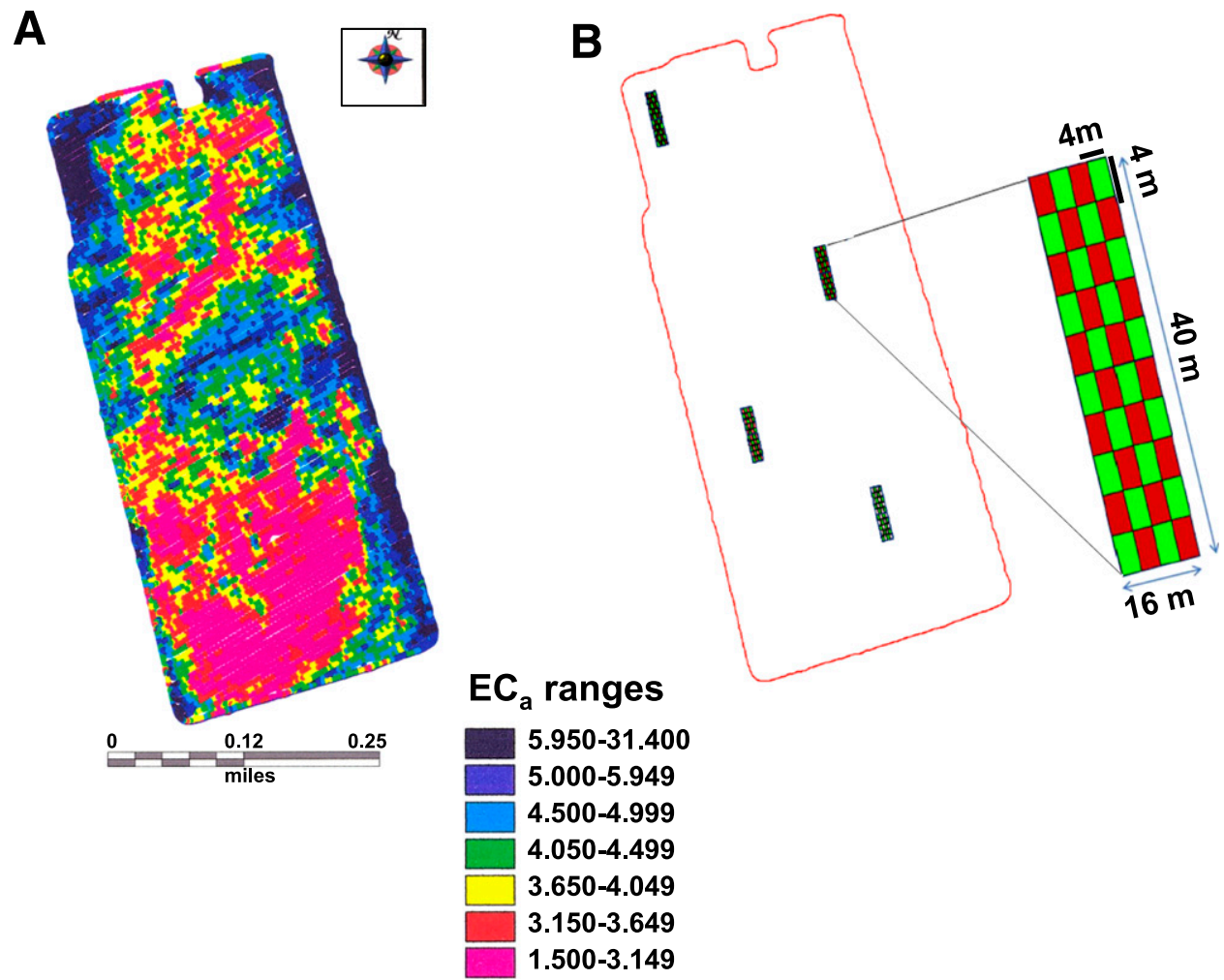

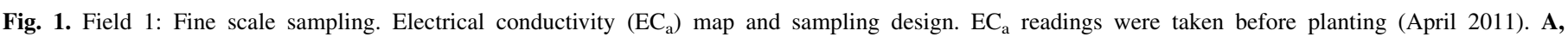

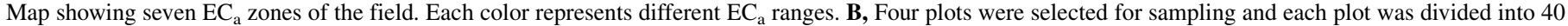
$(4 \times 4 \mathrm{~m})$ subplots. Eighty total samples per date $(40 / 2 \times 4=80)$. 
provides an indication of the spatial pattern of the counts. For uniformly distributed counts, variance is around zero and the expected DI is close to 0 ; for a random distribution, variance and mean are similar therefore DI is approximately 1 ; and for a clustered distribution, variance is relatively large, thus DI is greater than 1 . To assess the significance of the index, the $\chi^{2}$ test was used at 0.05 level of significance.

Because DI mainly tests for aggregation, regardless of type of sampling and density (50), and does not consider the spatial location of sampling points, Moran's index $(I)$ was calculated to evaluate the spatial pattern of RN abundance as a function of spatial distances (26). This index shows the degree of similarity/dissimilarity between nematode counts per sample (25). Values greater than 1 indicate aggregated distribution, and values lower than 1 indicate uniform distribution. Spatially independent data can be recognized when $I$ values are close to zero, which indicate absence of spatial autocorrelation. To test whether the differences in sampling distances in both fields affected the pattern of distribution of RN, spatial correlograms were constructed to display Moran's $I$ versus lag distances for each plot in field 1 and for the entire area in field 2. For field 1, nematode densities were interpolated using the gridded bivariate interpolation method (1), which uses nearby samples to fit a polynomial surface for each predicted point $(28,50)$ and it is useful for irregular data counts and small sampling size. For field 2, nematode densities were interpolated using the ordinary kriging technique (22), which requires larger data sets $(n>30)$ to show spatial structure $(17,46,52)$. Kriging analyses predict the interpolated data points by computing a weighted average of the known points using a variogram (covariance model) $(29,35)$.

Linear regression analyses were performed to determine the relationships between shallow $\mathrm{EC}_{\mathrm{a}}$ readings and soil particle size distribution as well as the relationship between $\mathrm{RN}$ densities and content of sand, silt, and clay. To infer particle size distribution based on soil $\mathrm{EC}_{\mathrm{a}}$, values were divided into ranges of 2 to $14 \mathrm{mS} / \mathrm{m}$ for field 1 and of 2 to $7 \mathrm{mS} / \mathrm{m}$ for field 2 . Percentage of sand was also partitioned in 5\% ranges to predict $\mathrm{RN}$ densities based on particle size distribution. ANOVA and regression analyses were performed in JMP, version 10 (47) and spatial statistical analyses were calculated in $\mathrm{R}$ version 3.0.2, using the autocorrelation module 3.03 (27) for Moran's I calculations, the Akima package (1) for linear interpolation analysis, and the gstat package for the interpolations and kriging analyses.

\section{RESULTS}

Soil texture and $\mathbf{E C}_{\mathbf{a}}$. Soil particle size distribution for the top $15-\mathrm{cm}$ layer for each of the four plots in field 1 is shown in Table 1. Plot 1 presented the highest sand content (75.9 to 81.9\%) found in the field and was the most uniform in soil type with all 20 samples being classified as loamy sand. Plot 3 presented the lowest sand content (21.9 to $50.0 \%)$ and was the most variable, containing 12 samples classified as loam, six as clay loam, and two as sandy clay loam. The majority of samples in plots 2 and 4 were sandy loam, and their variability in content of sand, silt, and clay was similar. In field 2 , soil type was less variable than in field 1 , and all soil samples were classified as one of three types: sandy clay loam, loamy sand, or sandy loam. Sand content in this field ranged from 53.8 to $87.9 \%$, and silt and clay content ranged from 6.0 to $20.0 \%$ and 6.2 to $28.2 \%$, respectively (Table 1).

Regression models showed a linear relationship between soil $\mathrm{EC}_{\mathrm{a}}$ and particle size distribution. A significant negative correlation between soil $\mathrm{EC}_{\mathrm{a}}$ and percent sand was detected in both fields $\left(\%\right.$ Sand $=89.37-3.41 \times \mathrm{EC}_{\mathrm{a}}, r^{2}=0.80, P<0.0001$ in field 1 ; and $\%$ Sand $=86.61-2.68 \times \mathrm{EC}_{\mathrm{a}}, r^{2}=0.84, P=0.0102$ in field 2). Silt and clay content showed significant positive relationships with soil $\mathrm{EC}_{\mathrm{a}}$ $\left(\%\right.$ Silt $=8.35+1.78 \times \mathrm{EC}_{\mathrm{a}}, r^{2}=0.73, P=0.0004, \%$ Clay $=2.31+$ $1.63 \times \mathrm{EC}_{\mathrm{a}}, r^{2}=0.84, P<0.0001$ in field 1 ; and $\%$ Silt $=7.23+$ $0.59 \times \mathrm{EC}_{\mathrm{a}}, r^{2}=0.87, P=0.0068, \%$ Clay $=6.14+2.10 \times \mathrm{EC}_{\mathrm{a}}$, $r^{2}=0.79, P=0.0178$ in field 2 ).

Population dynamics. The population densities observed after each crop in the rotation sequence for both fields behaved as expected, based on the known host suitability of the crops and cultivars (Table 2). Cotton caused increases in $\mathrm{RN}$ population densities in both fields, peanut and corn caused reductions, and soybean allowed moderate reproduction. $\mathrm{RN}$ population densities in the soil were higher in field 2 (minimum of $970 \mathrm{RN} / 100$ cubic centimeters [cc] of soil and maximum of $10,070 \mathrm{RN} / 100 \mathrm{cc}$ of soil) than in field 1 (minimum of $0 \mathrm{RN} / 100 \mathrm{cc}$ of soil and maximum of $6,930 \mathrm{RN} / 100 \mathrm{cc}$ of soil), and were highest after cotton in both fields. $\mathrm{RN}$ was present in all samples taken from field 2, but was absent in some of the samples taken in field 1, especially in plot 1. Among plots in field 1, significant differences were detected across the 3 years of the study $(\mathrm{df}=3, F=25.17, P<0.0001$ in 2011 ; df $=3$, $F=11.64, P<0.0001$ in 2012; and df $=3, F=5.26, P=0.0024$ in 2013). The highest densities of RN were found in plots 2 and 4 , with the highest density at harvest (6930 RN/100 cc of soil) in 2011 (cotton) for plot 4 . There was also a significant interaction between plot and sampling date $(\mathrm{df}=3, F=22.87, P<0.0001$ in 2011 ; $\mathrm{df}=2$, $F=8.99, P=0.0004$ in 2012). Other nematodes such as Hoplolaimus columbus, Helicotylenchus sp., and Meloidogyne incognita were detected in some of the plots, but $R$. reniformis was the most prevalent and abundant species.

Relationships between soil texture and RN densities. Regression models showed correlations between RN densities and particle size distribution. Significant relationships across sampling dates and in both fields were higher between RN densities and

TABLE 1. Soil particle size distribution (percentage content of sand, silt, clay) determined by the Bouyoucos method and corresponding soil electrical conductivity $\left(\mathrm{EC}_{\mathrm{a}}\right)$ readings $(0$ to $30 \mathrm{~cm})$ for each plot $(n=20)$ in field 1 and all sampling points in field $2(n=40)$

\begin{tabular}{|c|c|c|c|c|c|c|}
\hline \multirow[b]{2}{*}{ Field } & \multirow[b]{2}{*}{ Plot } & \multirow[b]{2}{*}{ Statistics } & \multicolumn{3}{|c|}{$\%$} & \multirow[b]{2}{*}{$\mathrm{EC}_{\mathrm{a}}(0-30 \mathrm{~cm})$} \\
\hline & & & Clay & Silt & Sand & \\
\hline \multirow[t]{12}{*}{ Field 1} & Plot 1 & Mean & 7.28 & 12.20 & 80.49 & 4.77 \\
\hline & & Standard error & 0.22 & 0.34 & 0.36 & 0.52 \\
\hline & & $\operatorname{Min}-\max$ & $6.1-8.2$ & $9.8-16$ & $75.9-81.9$ & $2.4-7.1$ \\
\hline & Plot 2 & Mean & 14.21 & 21.97 & 63.81 & 7.23 \\
\hline & & Standard error & 0.51 & 1.37 & 1.50 & 0.21 \\
\hline & & Min-max & $10.1-16.4$ & $11.8-34.1$ & $51.9-76$ & 5.2-9 \\
\hline & Plot 3 & Mean & 26.21 & 36.89 & 36.95 & 10.02 \\
\hline & & Standard error & 0.77 & 1.40 & 1.68 & 0.38 \\
\hline & & Min-max & $20.1-32.2$ & $28-48$ & $21.9-50$ & $7.8-13.4$ \\
\hline & Plot 4 & Mean & 15.38 & 20.46 & 64.16 & 10.06 \\
\hline & & Standard error & 0.66 & 0.36 & 0.90 & 0.44 \\
\hline & & Min-max & $10.1-22.1$ & $18.1-24$ & $53.9-71.8$ & $6.6-3.7$ \\
\hline \multirow[t]{3}{*}{ Field 2} & & Mean & 16.32 & 10.13 & 73.56 & 4.63 \\
\hline & & Standard error & 0.99 & 0.54 & 1.37 & 0.21 \\
\hline & & Min-max & $6.2-28.2$ & $6--20$ & $53.8-87.9$ & $2-7.3$ \\
\hline
\end{tabular}


percent sand and percent silt (Fig. 2). In field 1, correlations with sand and silt were higher after harvest than at planting, and they were highest when cotton (host) was planted at the beginning of the study. The level of correlation decreased with each subsequent nonhost: for sand, the $r^{2}$ dropped from $0.96[\mathrm{RN}=0.1096+$
$0.05484 \%$ Sand $\left.-0.0019(\% \text { Sand }-51.7576)^{2}\right]$ to $0.84[\mathrm{RN}=$ $0.9418+0.0328\left(\%\right.$ Sand $\left.-0.0016(\% \text { Sand }-54.1944)^{2}\right]$ after the first rotation with corn, and to $0.36[\mathrm{RN}=3.5440-0.0110 \%$ Sand $\left.0.0019(\% \text { Sand }-54.1944)^{2}\right]$ after the rotation with soybean. Likewise, correlations in field 2 were higher when cotton was

TABLE 2. Reniform nematode densities (individuals per 100 cubic centimeters of soil) found in the top $15 \mathrm{~cm}$ in each plot $(n=20)$ across sampling dates for field 1

\begin{tabular}{|c|c|c|c|c|c|c|}
\hline \multirow[b]{2}{*}{ Plot } & \multirow[b]{2}{*}{ Statistics } & \multicolumn{2}{|c|}{ Cotton 2011} & \multirow{2}{*}{$\frac{\text { Corn } 2012}{\text { Harvest }}$} & \multicolumn{2}{|c|}{ Soybean 2013} \\
\hline & & At plant & Harvest & & At plant & Harvest \\
\hline \multirow[t]{3}{*}{ Plot 1} & Mean & 0 & 0 & 0 & 0 & 0 \\
\hline & Standard error & - & - & - & - & - \\
\hline & $\mathrm{VMR}^{\mathrm{z}}$ & - & - & - & - & - \\
\hline \multirow[t]{2}{*}{ Plot 2} & Mean & 0 & $1,411.5$ & 566.5 & 50.5 & 1374.0 \\
\hline & Standard error & - & 296.10 & 200.25 & 16.93 & 366.58 \\
\hline \multirow{3}{*}{ Plot 3} & Standard error & 10.69 & 63.62 & 123.05 & 104.52 & 285.87 \\
\hline & Min-max & $0-170$ & $0-800$ & $0-2,040$ & $0-1,610$ & $0-5,180$ \\
\hline & VMR & 138.61 & 501.24 & $1,109.28$ & 921.88 & $2,627.68$ \\
\hline \multirow[t]{3}{*}{ Plot 4} & Mean & 92.2 & $2,475.5$ & $1,132.0$ & - & 285.0 \\
\hline & Standard error & 11.22 & 364.69 & 714.77 & - & 88.46 \\
\hline & Min-max & $33-204$ & $390-6,930$ & $150-2,590$ & - & $0-1,120$ \\
\hline
\end{tabular}

z Variance-to-mean ratio (dispersal index).

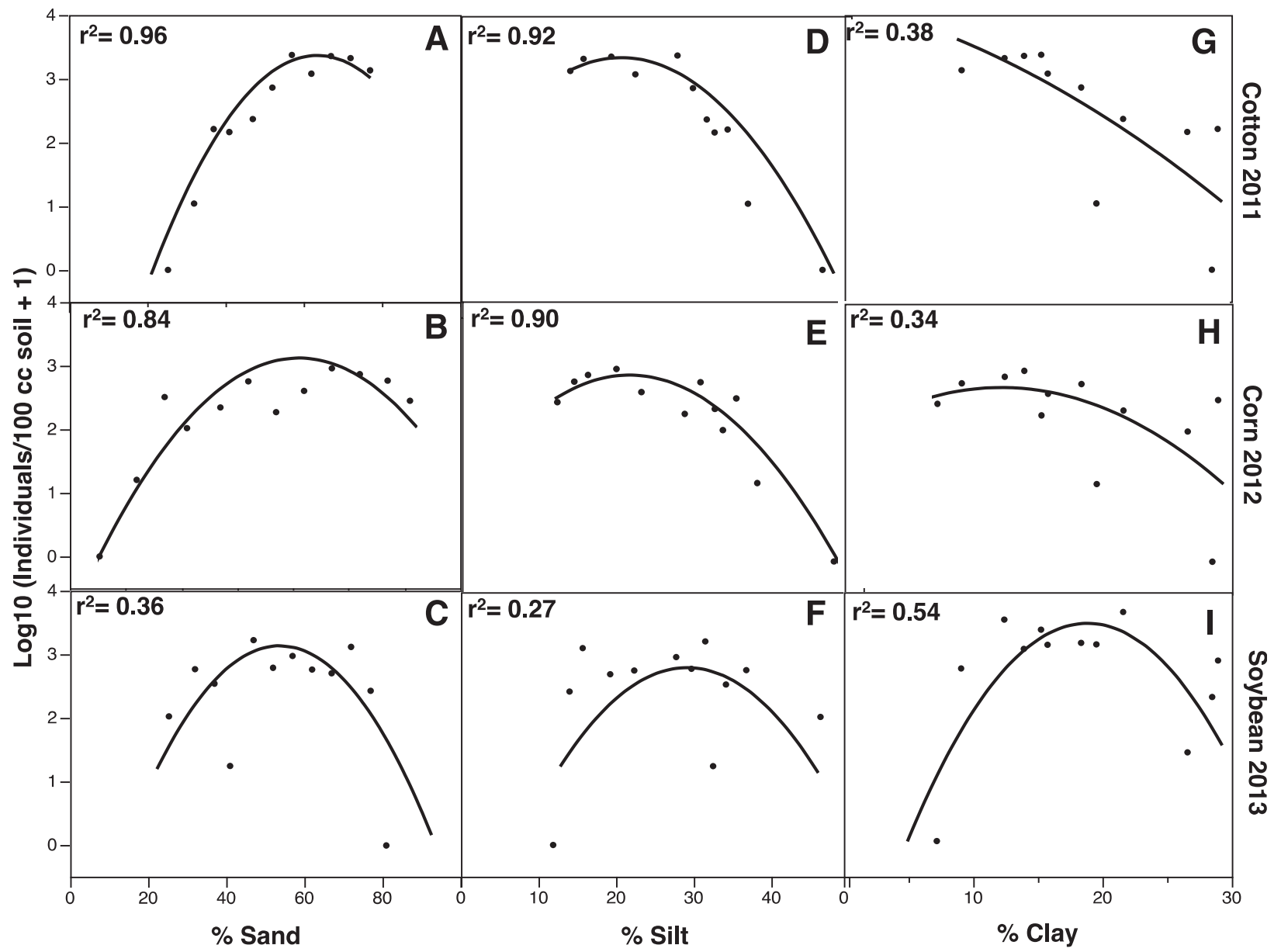

Fig. 2. Relationships between reniform nematode densities $\left(\log _{10}(\mathrm{RN} / 100\right.$ cubic centimeters [cc] of soil +1$\left.)\right)$ and soil particle size (\% sand, slit, and clay content) in field 1 for cotton (2011), corn (2012), and soybean (2013). Regression curves are described by quadratic functions. A, RN $=0.1096+0.0548 \%$ Sand -0.0019 $(\% \text { Sand }-51.7576)^{2} . \mathbf{B}, \mathrm{RN}=0.9418338+0.0328 \%$ Sand $-0.0016(\% \text { Sand }-54.1944)^{2} . \mathbf{C}, \mathrm{RN}=3.5440-0.0110 \%$ Sand $-0.0019(\% \text { Sand }-54.1944)^{2} . \mathbf{D}, \mathrm{RN}=$ $5.3896-0.0919 \%$ Silt $-0.0041(\% \text { Silt }-28.1860)^{2} . \mathbf{E}, \mathrm{RN}=4.1726-0.0573 \%$ Silt $-0.0041(\% \text { Silt }-26.8279)^{2} . \mathbf{F}, \mathrm{RN}=2.1639+0.0227 \%$ Silt $-0.0040(\% \text { Silt })^{2}$. $\mathbf{G}, \mathrm{RN}=4.6748-0.1134 \%$ Clay $-0.0016 *(\% \text { Clay }-19.0797)^{2} . \mathbf{H}, \mathrm{RN}=3.4867-0.0620 \%$ Clay $-0.0028(\% \text { Clay }-18.0893)^{2} . \mathbf{I}, \mathrm{RN}=2.4322+0.0345 \%$ Clay $0.0141(\% \text { Clay }-18.0893)^{2}$. 
planted $\left[\mathrm{RN}=3.8599-0.0064 \%\right.$ Sand $-0.0010(\% \text { Sand }-69.6252)^{2}$, $\left.r^{2}=0.81\right]$ and dropped dramatically after peanut (nonhost) $[\mathrm{RN}=$ $3.3240+0.0013 \%$ Sand $\left.-0.0005(\% \text { Sand }-69.625)^{2}, r^{2}=0.34\right]$. In all cases, quadratic (polynomial) models explained RN densities, showing a peak in nematode densities when percent sand was around $60 \%$ and a decline when percent sand was above 60 to $65 \%$. A decrease in $\mathrm{RN}$ densities was also observed when percent silt was above $20 \%$.

Horizontal distribution. The DI (VMR) was above 1 and the $\chi^{2}$ test significant $(P<0.001)$ for all sampling dates in both fields, indicating a clustered distribution of $\mathrm{RN}$ densities at plant and harvest during the 3 years (Tables 2 and 3). However, a significant neighborhood structure was only detected in field 1 when cotton and soybean were planted in 2011 and 2013, respectively (Figs. 3, 4, and 5). The average distance between two near sampling points (distance class) was $2.58 \pm 0.35 \mathrm{~m}$ and correlograms showed significant Moran's $I$ index values only for plots 3 and 4, indicating patches of 5 to $10 \mathrm{~m}$ in plot 3 and the presence of two patches of high RN densities of 8 to $10 \mathrm{~m}$ in plot 4 , with a transition area between patches in 2011 and 2013 (Figs. 3 and 5). Significant structure was not found for plot 2 at any date or for the plots in 2012 when corn was planted (Fig. 4), suggesting dependency of RN neighboring counts on a suitable host (cotton and soybean).

Interpolation maps revealed that $\mathrm{RN}$ densities were concentrated in the western part of plot 3 forming a single patch that disseminated up to the center of the plot, but the nematode was not found in the east area of the plot (Figs. 3, 4, and 5). Whereas for plot 4, maps displayed RN densities distributed across the plot with two peaks of high densities in 2011 and 2013 (Figs. 3 and 5). A dispersed pattern of RN counts was found in 2012 when corn was planted (Fig. 4). No

TABLE 3. Reniform nematode densities per 100 cubic centimeters of soil found in the top $15 \mathrm{~cm}$ for all sampling dates in field 2 in cotton $(n=40)$ and peanut $(n=40)$

\begin{tabular}{|c|c|c|c|c|c|c|c|c|}
\hline \multirow[b]{2}{*}{ Statistics } & \multicolumn{4}{|c|}{ Cotton 2012} & \multicolumn{4}{|c|}{ Peanut 2013} \\
\hline & At plant & Harvest & $F$ & $P>F$ & At plant & Harvest & $F$ & $P>F$ \\
\hline Mean & $1,877.5 b^{y}$ & $3,506.5 \mathrm{a}$ & 34.38 & $<0.0001$ & $2,377.75 \mathrm{a}$ & $940 \mathrm{~b}$ & 35.18 & $<0.0001$ \\
\hline Standard error & 131.34 & 284.04 & & & 212.52 & 127.12 & & \\
\hline Min-max & $580-4,390$ & $970-10,070$ & & & $230-6,190$ & $80-3,070$ & & \\
\hline $\mathrm{VMR}^{\mathrm{z}}$ & 367.52 & 920.36 & & & 87.1 & $1,201.5$ & & \\
\hline
\end{tabular}

y Means within the same row followed by the same letter are not significantly different $(P<0.05$; Tukey's [1953] HSD).

$\mathrm{z}$ Variance-to-mean ratio (dispersal index).

Plot 2

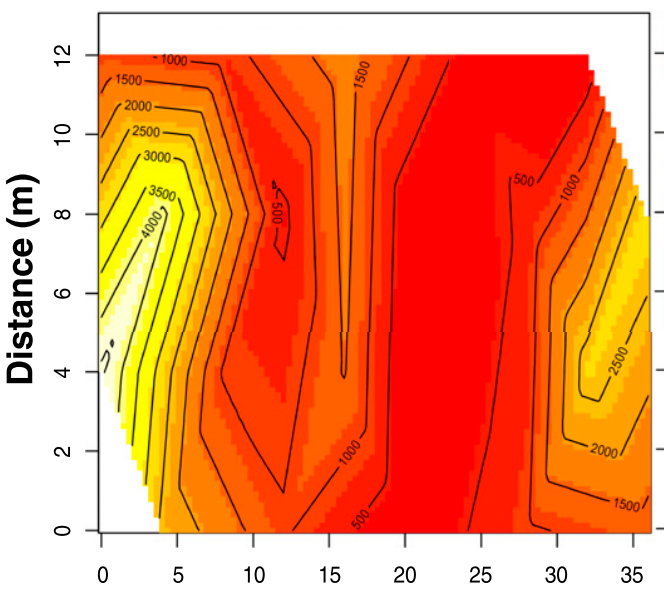

Plot 3

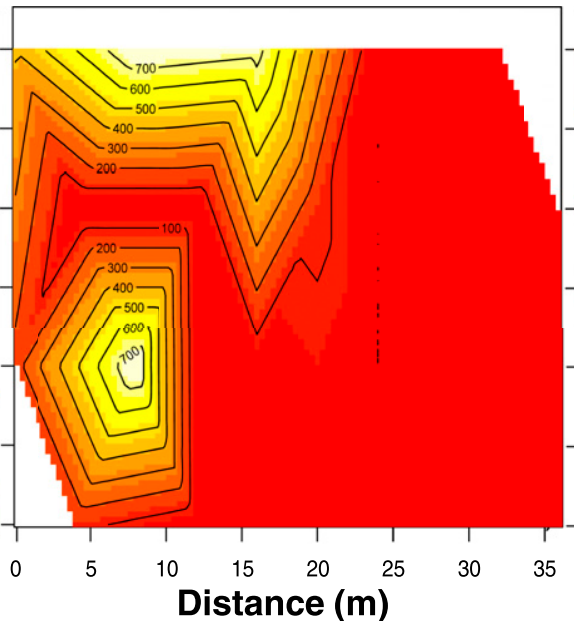

Plot 4

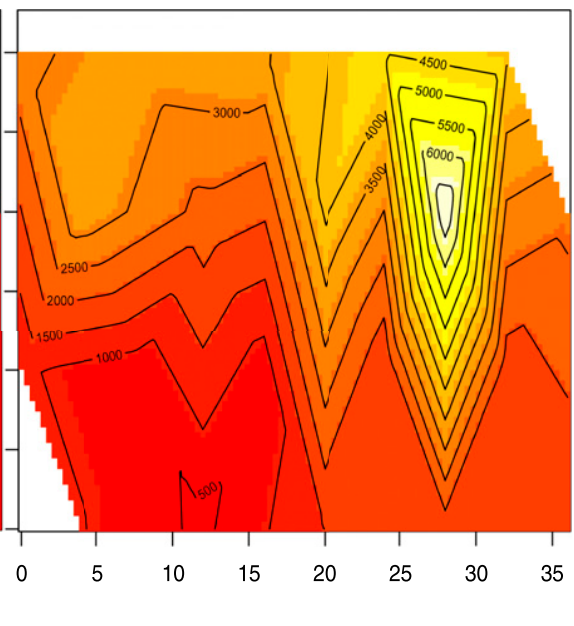

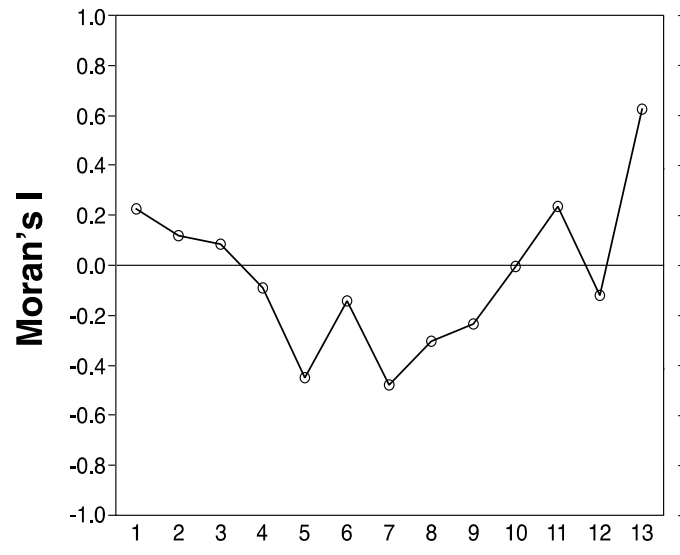
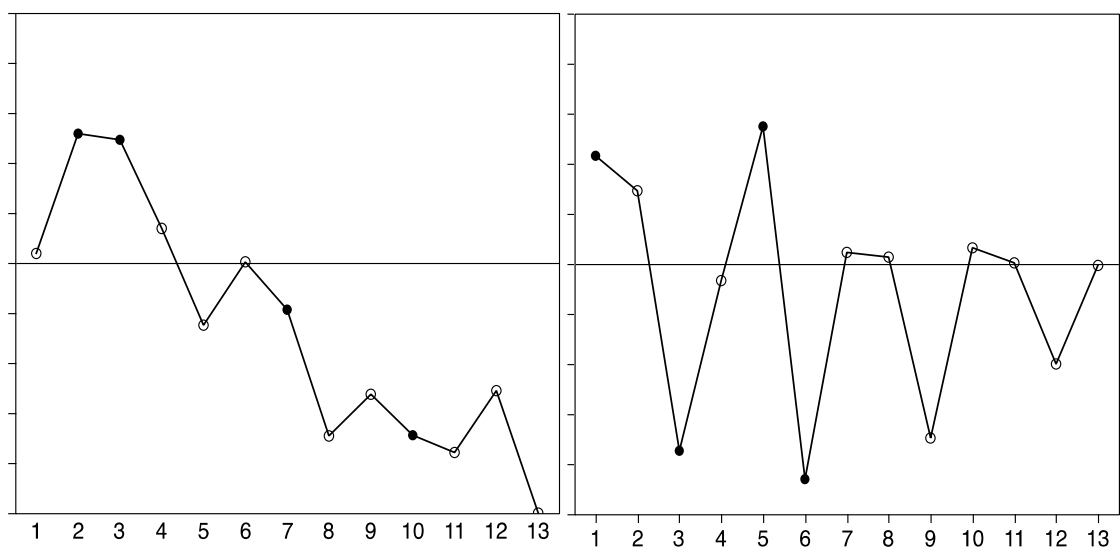

Distance classes $(\mathbf{m})$

Fig. 3. Interpolation maps and correlograms for field 1 showing Moran's $I$ index for plots 2, 3, and 4 in 2011 (cotton). Solid black circles indicate significant correlation at 0.05 level of significance. 
dependency was detected between neighbors of sampling locations in field 2, which suggests that the sampling scale with long distances between sampling points (minimum distance of $24.3 \mathrm{~m}$ ) was inadequate to detect the spatial autocorrelation that may exist between RN densities within this field. However, kriging maps based on spherical models showed areas in field 2 with higher densities of RN for all sampling dates (Fig. 6).

Vertical distribution. The first layer $(0$ to $15 \mathrm{~cm})$ contained seven samples classified as sandy loam, seven as sandy clay loam, and seven as loamy sand. In the second layer $(15$ to $30 \mathrm{~cm}) 10$ samples were loamy sand, four sandy clay loam, three sandy loam, two sandy clay, one clay loam, and one clay. In the third layer (30 to $60 \mathrm{~cm}), 13$ were clay, four sandy clay, two loamy sand, and two sandy loam. In the fourth layer $(>60 \mathrm{~cm}) 17$ samples were clay, two sandy clay, and one loamy sand. The highest sand content was found in the top $15 \mathrm{~cm}$ layer $(79.88 \%)$, and sand content declined as depth increased. Likewise, clay content was lower (6.55\%) in the shallow layer and increased consistently with soil depth. Silt content was higher and similar for the first two top layers (average of 13.57 and $14.71 \%$, respectively). Soil particle size distribution for each of the four layers is shown in Table 4.

For the first vertical sampling, after cotton harvest, $\mathrm{RN}$ densities were higher at 15 to $30 \mathrm{~cm}$ depth $(5,358.57 \mathrm{RN} / 100 \mathrm{cc}$ of soil $)$ and the top layer $(3,931.43 \mathrm{RN} / 100 \mathrm{cc}$ of soil) than in the rest of the soil profile. However, for the second deep sampling, after the peanut harvest, densities of RN were reduced in the top layers (1,546 and $2,460 \mathrm{RN} / 100 \mathrm{cc}$ of soil at 0 to 15 and 15 to $30 \mathrm{~cm}$, respectively) and higher densities were observed at 30 to $60 \mathrm{~cm}$ depth (2,813.5 RN/
$100 \mathrm{cc}$ of soil), which were significantly different from the other layers (Fig. 7).

\section{DISCUSSION}

Previous studies have shown that silt and clay content correlate positively with $\mathrm{RN}$ densities $(8,12,21,33,44)$. Our data show that densities of RN are better correlated with sand content, with a positive correlation for values of sand up to $60 \%$ and a negative correlation for $>60 \%$ sand. Similarly, we found a positive correlation with silt content up to $20 \%$ and a negative correlation for $>20 \%$ silt. We believe that these changes in correlation behavior at approximately $60 \%$ sand and $20 \%$ silt help explain some of the apparent contradictions reported in different $\mathrm{RN}$ and soil texture relationship studies. It is also important to consider the range of variability in soil textures used to determine the correlations between soil particle size and nematode densities. Our fine-scale sampling in field 1, with sand content ranging from 21 to $82 \%$, illustrates that sand content is a highly adequate predictor of RN density. However, when fewer samples are taken in a larger field with more uniform sand content (54 to 88\%), percent sand is less reliable a predictor of $\mathrm{RN}$ densities. Equally important is to consider $\mathrm{RN}$ densities themselves. We hypothesize that very high $\mathrm{RN}$ densities within a field, like the ones observed in field 2, contribute to obscuring the effect of soil texture. Ortiz et al. (36) report a similar observation, with high and more uniform root-knot nematode densities affecting the predictions and the determination of factors that drive the distribution of this nematode in cotton fields.
Plot 2
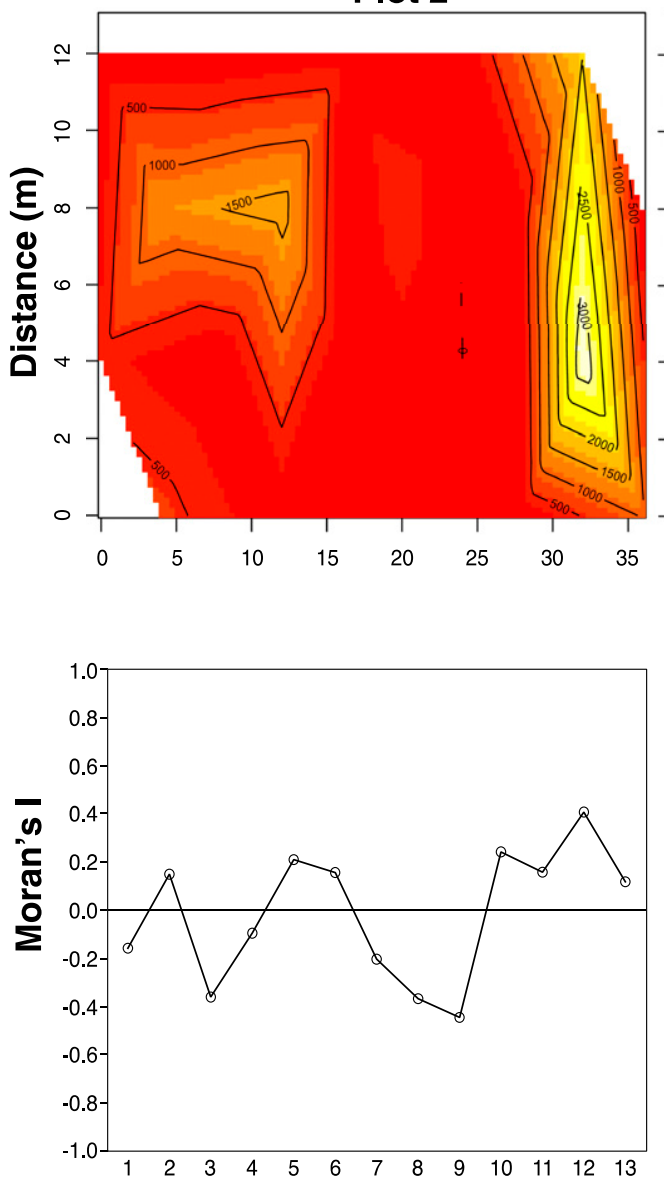

Plot 3
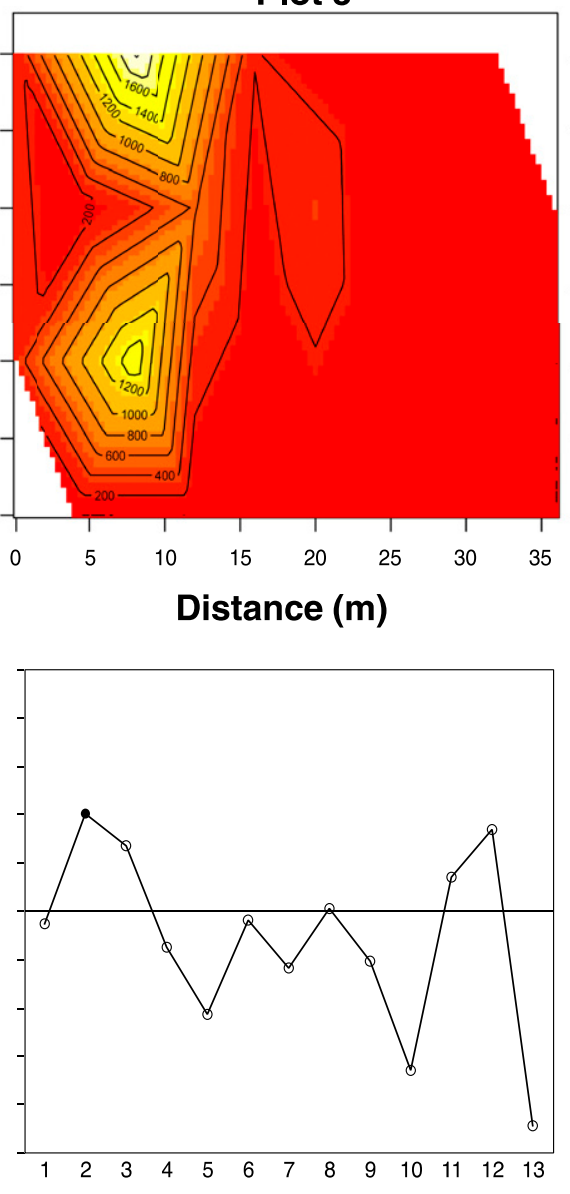

Distance classes (m)
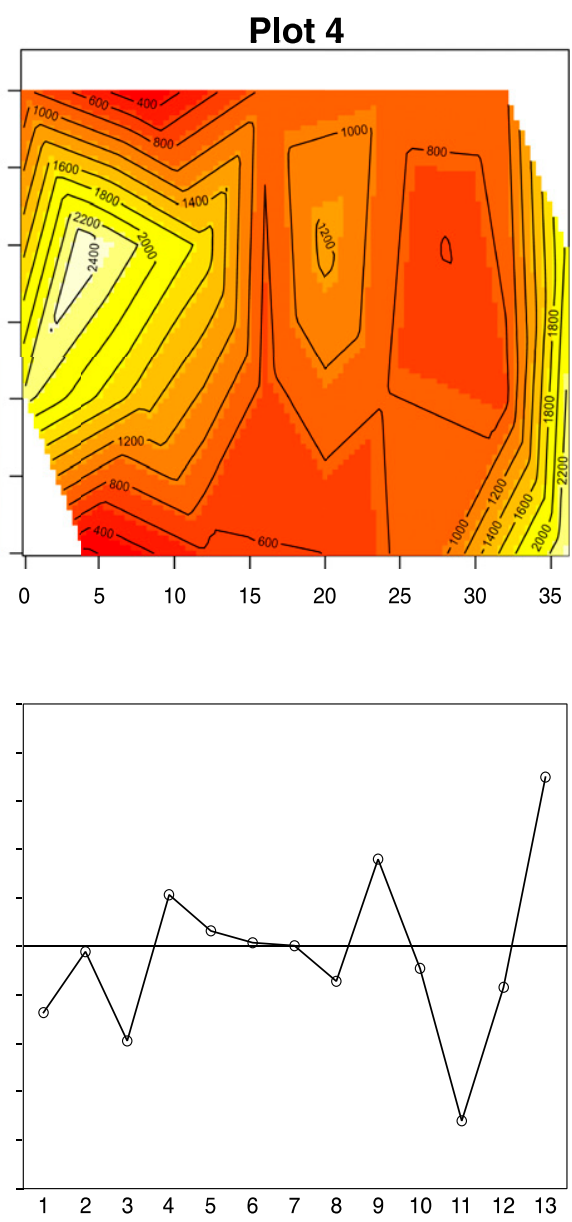

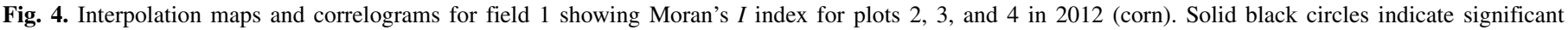
correlation at 0.05 level of significance. 
Site-specific management tactics are more applicable and more effective on nematode species that have an aggregated spatial distribution (38) and require spatial patterns to be highly structured for the creation of accurate maps (2). Our study shows that RN displays an aggregated pattern of spatial distribution, characterized by DI values significantly higher than 1 . These high DI values are explained by the large variance in nematode counts for both fields. However, the spatial pattern changed over time depending on the host and also varied in the different plots studied. Moreover, we found lack of spatial autocorrelation for all plots in field 1 when corn, a nonhost for RN, was planted in 2012. It is plausible that when a suitable host is not present, all vermiform stages of the nematode are more dispersed and therefore show a more random distribution pattern. It is pertinent to note that males and second-stage juveniles (J2) are typically the only stages that are mobile in the soil for other sedentary plant-pathogenic nematodes important in field crops, like root-knot and cyst, but for RN mobile stages include $\mathrm{J} 2, \mathrm{~J} 3, \mathrm{~J} 4$, males, and young females. The question of whether all vermiform stages or just the infective stages (young females) change their spatial distribution in response to the presence or absence of the host is yet to be answered.

The clustered distribution found for RN suggests that sitespecific management may be appropriate for this nematode, especially when individual fields show high structure in soil texture and RN densities. Site-specific management may require more intensive sampling than other conventional management programs (18). However, if the pattern of aggregation of the nematode is understood, this may facilitate the development of sampling strategies. In this study, a scale of $4 \times 4 \mathrm{~m}$ was sufficient to detect the aggregation pattern and size of the patches of $\mathrm{RN}$ that ranged from 8 to $12 \mathrm{~m}$, and clusters were detected regardless of the soil type. Future studies could consider larger sampling distances, over $8 \mathrm{~m}$, which was the minimum size of the patches found in our study.

We believe that soil texture is a useful starting point for delineation of RN management zones. However, the observed differences in $\mathrm{EC}_{\mathrm{a}}$ readings and $\mathrm{RN}$ densities for plots 2 and 4, which were found to have the same soil type (sandy loam) indicate that other drivers of $\mathrm{RN}$ distribution are at play. We hypothesize that for field 1, additional drivers of variability of $\mathrm{EC}_{\mathrm{a}}$ readings and $\mathrm{RN}$ densities were elevation and water drainage patterns, which is consistent with what other researchers have reported $(8,14,32)$. However, depending on the level of resolution of the delineated potential management zones, plots 2 and 4 could have fallen within the same management zone. Water retention capacity is the most likely driver of the correlations observed between RN density and sand content. Although we did not measure soil water content directly in this study, $\mathrm{EC}_{\mathrm{a}}$ readings reflect differences in water content. Other factors that may affect the distribution of $\mathrm{RN}$ in the field, and that may weigh differently in individual fields, include initial introduction of nematodes to the field and subsequent dissemination pattern, field crop history, and other edaphic factors such as soil bulk density and soil nutrient status.

RN probably responds to various stimuli interactively or sequentially in a manner that increases the chances of completing
Plot 2

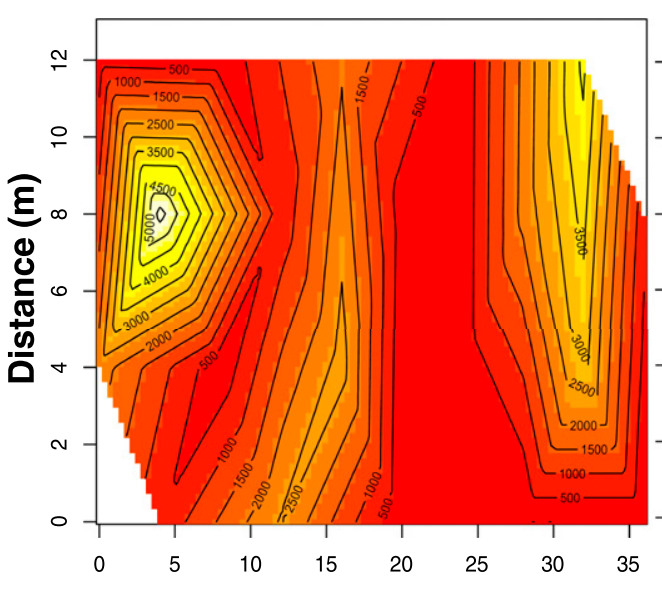

Plot 3

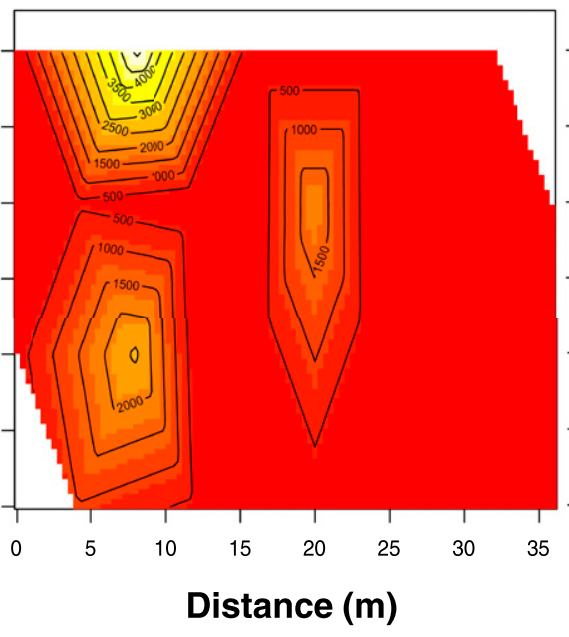

Plot 4

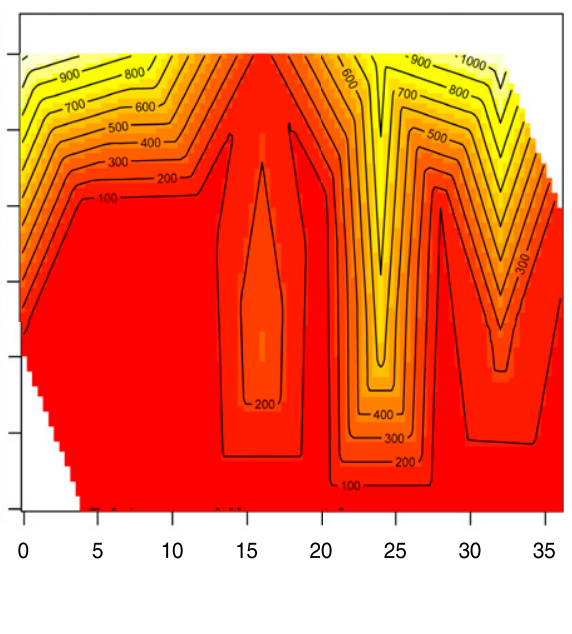

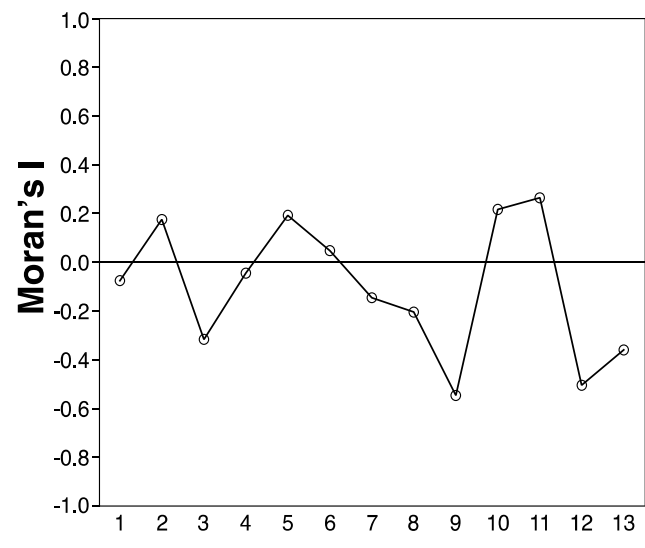
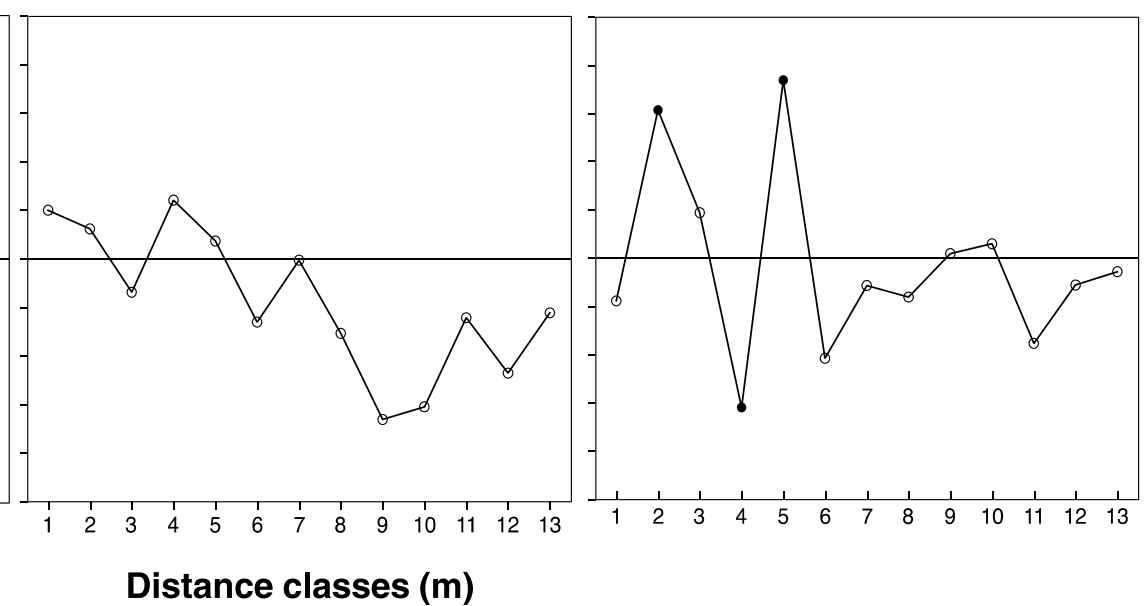

Fig. 5. Interpolation maps and correlograms for field 1 showing Moran's $I$ index for plots 2, 3, and 4 in 2013 (soybean). Solid black circles indicate significant correlation at 0.05 level of significance. 

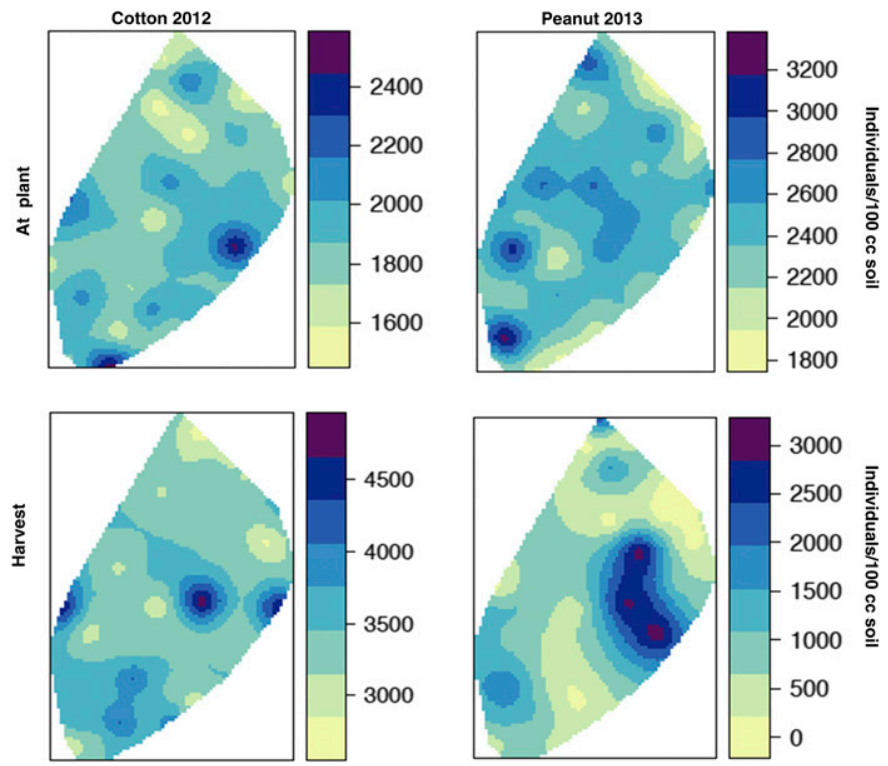

Fig. 6. Reniform nematode densities (individuals/100 cubic centimeters [cc] of soil) in the top $15 \mathrm{~cm}$ interpolated by ordinary kriging at each sampling date in field 2 .

TABLE 4. Soil particle size distribution (percentage content of sand, silt, and clay) determined by the Bouyoucos method for vertical core samples from field $2(n=21)$

\begin{tabular}{llccc}
\hline & & \multicolumn{3}{c}{$\%$} \\
\cline { 3 - 5 } Core section & Statistics & \multicolumn{1}{c}{ Sand } & \multicolumn{1}{c}{ Silt } & Clay \\
\hline 0 to $15 \mathrm{~cm}$ & Mean & 79.88 & 13.57 & 6.55 \\
& Standard error & 2.05 & 1.03 & 1.32 \\
\multirow{5}{*}{15 to $30 \mathrm{~cm}$} & Min-max & $59.37-89.23$ & $8.11-25.00$ & $1.52-18.75$ \\
& Mean & 68.47 & 14.71 & 16.82 \\
& Standard error & 2.88 & 2.31 & 3.87 \\
30 to $60 \mathrm{~cm}$ & Min-max & $35.71-85.37$ & $0-35.71$ & $2.17-56.14$ \\
& Mean & 29.85 & 4.31 & 65.48 \\
& Standard error & 6.14 & 2.07 & 7.80 \\
$>60 \mathrm{~cm}$ & Min-max & $0-80.00$ & $0-30.77$ & $2.22-100$ \\
& Mean & 12.51 & 3.94 & 83.55 \\
& Standard error & 6.70 & 2.82 & 9.09 \\
& Min-max & $0-77.08$ & $0-38.30$ & $2.08-100$ \\
\hline
\end{tabular}

the life cycle. Carbon dioxide, for example, has been shown to attract several nematode species (41) and has been proposed as critical for root finding and a determinant of the vertical distribution of nematodes in the soil. Likewise, movement of $\mathrm{RN}$ along vertical gradients of temperature (40) and $\mathrm{CO}_{2}$ (41) simulated in sand columns have shown that $\mathrm{RN}$ has greater downward movement than $M$. incognita. When the soil warms, RN can move away from the heat (downward) and when the soil cools, it moves toward the heat (also downward). Downward movement of RN was associated with head-down descent in water and was suggested to result from differences in the specific gravity of the two ends of the body (40). In our study, we observed a downward movement of RN when a nonhost (peanut) is planted. Densities were higher in the root zone ( 0 to $30 \mathrm{~cm}$ ) when cotton (host) was present, but below the root zone (highest at 30 to $60 \mathrm{~cm}$ ) with peanut.

Sampling for vertical distribution in field 2 indicated the highest $\mathrm{RN}$ densities are found between 15 and $30 \mathrm{~cm}$ deep, followed by the top 15-cm layer. However, after peanut harvest, RN densities decreased at these depths and remained constant for the other layers, which also presented high densities of RN (over 2,000 RN/100 cc of soil for 30 to $60 \mathrm{~cm}$ and over 1,000 RN/100 cc of soil for $>60 \mathrm{~cm}$ ). Westphal and Smart (53) and Robinson et al. $(42,43)$ found higher densities of RN at depths below $30 \mathrm{~cm}$, concluding that RN densities did not follow the root system. In their studies, vertical changes in soil texture were limited and assumed to not be a factor affecting changes in population density. Sand content in the Westphal and Smart (53) study ranged from an average of $69 \%$ in the 0 to $30 \mathrm{~cm}$ layer to $83 \%$ sand in the 60 to $90 \mathrm{~cm}$ layer. In our study, sand content is reduced drastically with depth, from an average of $79.88 \%$ sand in the 0 to $30 \mathrm{~cm}$ layer to an average of $12.51 \%$ in the $>60 \mathrm{~cm}$ layer. In addition to the influence of soil texture, there is evidence for a host root effect. In our study, RN densities were higher when the majority of the cotton roots were present: the top $30 \mathrm{~cm}$. Nevertheless, it is important to consider that RN densities in the field where we did the vertical sampling were high (above thresholds for cotton in South Carolina), with high densities found across the four layers, including $>60 \mathrm{~cm}$, and much higher than those found in the two studies cited above.

Crop rotation with corn, peanut, or resistant soybean is a prescribed method for RN management for cotton producers in several states $(9,11,37)$. Cotton yields have been shown to increase following corn or resistant soybean versus fields planted with

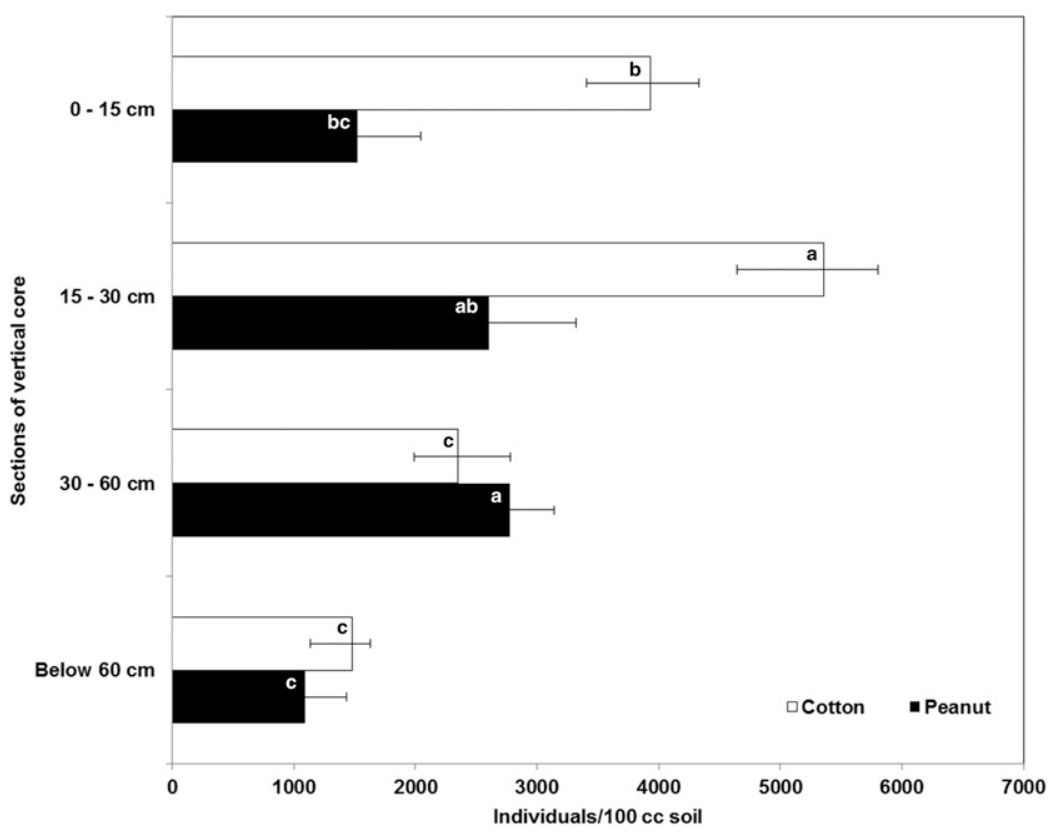

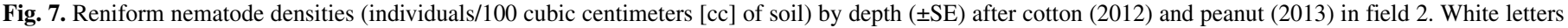
indicate statistical comparisons within cotton; black letters indicate statistical comparisons within peanut (Tukey's means comparison test, $P<0.001)$. 
continuous cotton in North Carolina, Georgia, Arkansas, and Alabama $(9,11)$. Researchers have found no significant differences among cultivars or corn hybrids used in rotations, suggesting it is a species effect and not dependent on cultivar (9). Crop rotation has also been shown to influence the genetic population structure of RN (24), but our study is the first to show an effect of crop on the spatial distribution pattern of $\mathrm{RN}$ in the field.

Most management decisions are based on $\mathrm{RN}$ densities found in the top $15 \mathrm{~cm}$, but it is important to be aware of the potential variability in the vertical distribution of the nematode and the influence of rotation crops on the distribution patterns. The understanding of the horizontal and vertical distribution of $\mathrm{RN}$ is essential for choosing adequate sampling strategies as well as for delineating zones for site-specific management. This study shows that sand content is a good predictor of the variability of $\mathrm{RN}$ densities in a field as inferred by soil shallow $\mathrm{EC}_{\mathrm{a}}$ readings and describes the aggregated patterns of distribution of the nematode.

\section{ACKNOWLEDGMENTS}

Research was supported by the United States Department of AgricultureNIFA, Contract Number 2010-51101-21785.

\section{LITERATURE CITED}

1. Akima, H. 1978. A method of bivariate interpolation and smooth surface fitting for values given at irregularly distributed points. ACM Trans. Math. Softw. 4:2.

2. Avendaño, F., Pierce, F. J., Schabenberger, O., and Melakeberhan, H. 2004. The spatial distribution of soybean cyst nematode in relation to soil texture and soil map unit. Agron. J. 96:181-194.

3. Avendaño, F., Schabenberger, O., Pierce, F. J., and Melakeberhan, H. 2003. Geostatistical analysis of field spatial distribution patterns of soybean cyst nematode. Agron. J. 95:936-948.

4. Baird, R. E., Davis, R. F., Alt, B. G., Mullinix, B. G., and Padgett, G. B. 1996. Frequency and geographical distribution of plant-parasitic nematodes on cotton in Georgia. Suppl. J. Nematol. 28:661-667.

5. Blasingame, D., and Patel, M. V. 2013. Cotton disease loss estimate committee report. Proc. Beltwide Cotton Conf. National Cotton Council 1: 1242-1246.

6. Bouyoucos, G. J. 1962. Hydrometer method improved for making particle size analyses of soils. Agron. J. 54:464-465.

7. Brodie, B. B. 1976. Vertical distribution of three nematode species in relation to certain soil properties. J. Nematol. 8:243-247.

8. Davis, R. F., Aryal, S. K., Perry, C. D., Sullivan, D. G., Timper, P., Ortiz, B. V., Stevenson, K. L., Vellidis, G., and Hawkins, G. 2013. Utilizing management zones for Rotylenchulus reniformis in cotton: Effects on nematode levels, crop damage, and Pasteuria sp. Crop Prot. 50:53-60.

9. Davis, R. F., Koenning, S. R., Kemerait, R. C., Cummings, T. D., and Shurley, W. D. 2003. Rotylenchulus reniformis management in cotton with crop rotation. J. Nematol. 35:58-64.

10. Gaur, H., and Perry, R. N. 1991. The biology and control of the plant parasitic nematode Rotylenchulus reniformis. Agric. Zoo. Rev. 4:177-212.

11. Gazaway, W. S., Akridge, J. R., and McLean, K. 2000. Impact of various crop rotations and various winter cover crops on reniform nematode in cotton. Proc. Beltwide Cotton Conf. National Cotton Council 1:162-163.

12. Heald, C. M., and Robinson, A. F. 1990. Survey of current distribution of Rotylenchulus reniformis in the United States. Suppl. J. Nematol. 22: 695-699.

13. Heald, C. M., and Thames, W. H. 1982. The reniform nematode, Rotylenchulus reniformis. Nematology in the Southern region of the United States.R. D. Riggs, ed. Arkansas Agric. Exp. Stn. Southern Cooperative Series Bulletin 276.

14. Herring, S., Koenning, S. R., and Heitman, J. L. 2010. Impact of Rotylenchulus reniformis on cotton yield as affected by soil texture and irrigation. J. Nematol. 42:319-323.

15. Jenkins, W. R. 1964. A rapid centrifugal-flotation technique for separating nematodes from soil. Plant Dis. Rep. 48:692.

16. Jones, J. T., Haegeman, A., Danchin, E. G. J., Gaur, H. S., Helder, J., Jones, M. G. K., Kikuchi, T., Manzanilla-López, R., Palomares-Rius, J. E., Wesemael, W. M. L., and Perry, R. N. 2013. Top 10 plant-parasitic nematodes in molecular plant pathology. Mol. Plant Pathol. 14:946-961.

17. Journel, A. G., and Huijbregts, C. J. 1978. Mining Geostatistics. Academic Press, London.
18. Karimzadeh, R., Hejazi, M. J., Helali, H., Iranipour, S., and Mohammadi, S. A. 2011. Analysis of the spatio-temporal distribution of Eurogaster intergriceps (Hemiptera: Scutelleridae) by using spatial analysis by distance indices and geostatistics. Environ. Entomol. 40:1253-1265.

19. Khalilian, A., Mueller, J. D., Han, Y. J., and Wolak, F. J. 2001. Predicting cotton nematode distribution utilizing soil electrical conductivity. Proc. Beltwide Cotton Conf. National Cotton Council 1:146-149.

20. Koenning, S. R., Kirkpatrick, T. L., Starr, J. L., Wrather, J. A., Walker, N. R., and Mueller, J. D. 2004. Plant-parasitic nematodes attacking cotton in the United States: Old and emerging production challenges. Plant Dis. 88:100-113.

21. Koenning, S. R., Walters, S. A., and Barker, K. R. 1996. Impact of soil texture on the reproductive and damage potentials of Rotylenchulus reniformis and Meloidogyne incognita on cotton. J. Nematol. 28:527-536.

22. Krige, D. G. 1966. Two-dimensional weighted moving average trend surfaces for ore-evaluation. J. S. Afr. Inst. Min. Metall. 66:13-38.

23. Lawrence, G. W., and McLean, K. S. 1996. Reniform nematode and cotton production in Mississippi. Proc. Beltwide Cotton Conf. National Cotton Council 1:251-253.

24. Leach, M., Agudelo, P., and Lawton-Rauh, A. 2012. Effect of crop rotations on Rotylenchulus reniformis population structure. Plant Dis. 96:24-29.

25. Legendre, P. 1993. Spatial autocorrelation-trouble or new paradigm. Ecology 74:1659-1673.

26. Legendre, P., and Legendre, L. 1998. Numerical Ecology. Developments in Environmental Modelling, Vol. 20. Elsevier, Amsterdam. http://www. fas.umontreal.ca/biol/legendre/numecol.html

27. Legendre, P., and Vaudor, A. 1991. The R Package: Multidimensional Analysis, Spatial Analysis. Département de Sciences Biologiques, Université de Montréal.

28. Li, J., and Heap, A. D. 2008. A Review of Spatial Interpolation Methods for Environmental Scientists. Geoscience Australia, Record 2008/23.

29. Matheron, G. 1963. Principles of geostatistics. Econ. Geol. 58:1246-1266.

30. Midgarden, D., Fleischer, S. J., Weisz, R., and Smilowitz, Z. 1997. Sitespecific integrated pest management impact on development of esfenvalerate resistance in Colorado potato beetle (Coleoptera: Chrysomelidae) and on densities of natural enemies. J. Econ. Entomol. 90:855-867.

31. Monfort, W. S., Kirkpatrick, T. L., Rothrock, C. S., and Mauromoustakos, A. 2007. Potential for site-specific management of Meloidogyne incognita in cotton using soil textural zones. J. Nematol. 39:1-8.

32. Monfort, W. S., Kirkpatrick, T. L., Rothrock, C. S., and Mauromoustakos, A. 2008. Spread of Rotylenchulus reniformis in an Arkansas cotton field over a four-year period. J. Nematol. 40:161-166.

33. Moore, S. R., and Lawrence, K. S. 2013. The effect of soil texture and irrigation on Rotylenchulus reniformis and cotton. J. Nematol. 45:99-105.

34. Mueller, J. D., Khalilian, A., Monfort, W. S., Davis, R. F., Kirkpatrick, T. L., Ortiz, B. V., and Henderson, W. G. 2010. Site-specific detection and management of nematodes. Pages 385-402 in: Precision Crop Protection the Challenge and Use of Heterogeneity. E.-C. Oerke, R. Gerhards, G. Menz, and R. A. Sikora, eds. Springer, Berlin.

35. Olea, R. A. 2006. A six-step practical approach to semivariogram modeling. Stochastic Environ. Res. Risk Assess. 20:307-318.

36. Ortiz, B. V., Perry, C., Goovaerts, P., Vellidis, G., and Sullivan, D. 2010. Geostatistical modeling of the spatial variability and risk areas of southern root-knot nematodes in relation to soil properties. Geoderma 156:243-252.

37. Overstreet, C., and McGawley, E. C. 1993. The reniform nematode in Louisiana cotton production. Beltwide Cotton Conf. Proc. 1:231.

38. Park, Y. L., Krell, R. K., and Carroll, M. 2007. Theory, technology, and practice of site-specific insect pest management. J. Asia Pac. Entomol. 10: 89-101.

39. Plunkett, D. E., Kirkpatrick, T. L., Harmon, B., Matlock, R., Robertson, W. C., and Ross, J. 2003. Using an integrated pest management rotational crop program to suppress reniform nematode Proc. Beltwide Cotton Conf. National Cotton Council 1:25-28.

40. Robinson, A. F. 1994. Movement of five nematode species through sand subjected to natural temperature gradient. J. Nematol. 26:46-58.

41. Robinson, A. F. 1995. Optimal release rates for attracting Meloidogyne incognita, Rotylenchulus reniformis, and other nematodes to carbon dioxide in sand. J. Nematol. 27:42-50.

42. Robinson, A. F., Bradford, J. M., Cook, C. G., Kirkpatrick, T. L., McGawley, E. C., Overstreet, C., and Padgett, B. 2000. Vertical distribution of the reniform nematode in the upper 1.5 meters of soil on nine farms in Arkansas, Louisiana, and Texas. Proc. Beltwide Cotton Conf. National Cotton Council 1:564.

43. Robinson, A. F., Cook, C. G., Westphal, A., and Bradford, J. M. 2005. Rotylenchulus reniformis below plow depth suppresses cotton yield and root growth. J. Nematol. 27:42-50.

44. Robinson, A. F., Heald, C. M., Flanagan, S. L., Thames, W. H., and Amador, J. 1987. Geographical distributions of Rotylenchulus reniformis, Meloidogyne incognita, and Tylenchulus semipenetrans in the Lower Rio 
Grande Valley as related to soil texture and land use. Ann. Appl. Nematol. $1: 20-25$.

45. Robinson, A. F., Inserra, R. N., Caswell-Chen, E. P., Vovlas, N., and Troccoli, A. 19797. Rotylenchulus species: Identification, distribution, host ranges, and crop plant resistance. Nematropica 27:127-180.

46. Rossi, R. E., Mulla, D. J., Journel, A. G., and Franz, E. H. 1992. Geostatistical tools for modeling and interpreting ecological spatial dependence. Ecol. Monogr. 62:277-314.

47. SAS Institute Inc. 2012. Using JMP 10. SAS Institute Inc., Cary, NC.

48. Taylor, L. R. 1961. Aggregation, variance and the mean. Nature 189: $732-735$.
49. Taylor, L. R. 1984. Assessing and interpreting the spatial distributions of insect populations. Annu. Rev. Entomol. 29:321-357.

50. Venables, W. N., and Ripley, B. D. 2002. Modern Applied Statistics with S-Plus. Springer-Verlag, New York.

51. Wallace, H. R. 1968. The dynamics of nematode movement. Annu. Rev. Phytopathol. 6:91-114.

52. Webster, R., and Oliver, M. 2001. Geostatistics for Environmental Scientists. John Wiley \& Sons, Ltd., Chichester.

53. Westphal, A., and Smart, J. R. 2003. Depth distribution of Rotylenchulus reniformis under different tillage and crop sequence systems. Phytopathology 93:1182-1189. 